\title{
Determinação quantitativa de parâmetros texturais de arenitos eólicos através de análise de imagens digitais de seções delgadas
}

\author{
Ana Lúcia D. Gesicki', Isaac Jamil Sayeg ${ }^{2}$, Daiane Katya Curti², Paulo César Boggiani² \\ \& Paulo César Fonseca Giannini ${ }^{2}$
}

\begin{abstract}
Resumo Análise de imagens em seções delgadas de amostras de calha de arenitos das formações Pirambóia e Botucatu, provenientes de poço de captação de água do município de Barretos, SP, nortearam o desenvolvimento de rotinas para quantificação da porosidade e dos índices de empacotamento de Kahn (1956). O processo de análise de imagem utilizado foi a segmentação por limiarização dos histogramas dos componentes HSI (matiz, saturação e intensidade) da imagem colorida, tendo em vista o contraste dos componentes óticos da cena microscópica. Estes componentes subdividem-se em poros azuis, coloridos por impregnação prévia da rocha com resina e corante, e arcabouço de grãos e cimento (não poros) incolores. As rotinas de análise envolvem etapas de aquisição de imagens, segmentação por limiares, correção automática de binário, correção manual de binário e medição de binário. As principais fontes de imprecisão da análise de imagem são a presença de microporosidade dispersa em cimentos de argila e o efeito de cunha das bordas de poro. Os arenitos analisados apresentam macroporosidades altas, com médias de 39,55\% e 28,47\%, respectivamente, para as formações Pirambóia e Botucatu. A porção superior da Formação Pirambóia, próximo ao contato com a Formação Botucatu, por outro lado, apresenta horizontes com baixa porosidade (média 3,23\%) devido à obstrução do espaço intergranular por cimento carbonático. $\mathrm{O}$ arcabouço das rochas de ambas unidades é aberto, com densidade de empacotamento variando de $59 \%$ a $82 \%$ e proximidade de empacotamento inferior a $25 \%$.
\end{abstract}

Palavras-chave: segmentação, porosidade, empacotamento, Aqüífero Guarani.

\begin{abstract}
Determination of textural parameters of aeolian sandstones using thin section digital image analysis. Cutting sandstone samples from Pirambóia and Botucatu formations, collected from a water well localized in Barretos city, São Paulo State, Brazil, were analysed in terms of microscopic digital image of thin sections to determine the porosity and packing index (sensu Kahn 1956) of the sandstones. Two routines of digital image analysis were developed using thresholding segmentation method of the HSI (hue, saturation and intensity) components of the color image. The optical components of blue-dyed epoxy-impregnated sandstones samples are characterized by bluish pore space and uncolored grains and cements (non pore component), which present bimodal distribution of the optical component histograms, mainly hue component. The Pirambóia and Botucatu formations are high porosity rocks, average 39,5\% and 28,47\%, respectively. The uppermost Pirambóia Formation is characterized by the poorer porosity horizons (average 3,23\%) due to the presence of carbonate cement. The packing of the sandstones are in general open, with indexes varying from $59 \%$ and $82 \%$ (density packing) and lower than $25 \%$ (proximity packing).
\end{abstract}

Keywords: segmentation, porosity, packing, Guarani Aquifer System.

INTRODUÇÃO Os parâmetros texturais de um sedimento ou rocha sedimentar podem ser definidos em função de tamanho (granulometria e seleção), forma (arredondamento e esfericidade) e arranjo espacial (orientação e empacotamento) dos elementos deposicionais e do espaço poroso (Griffiths 1952). Ao longo da diagênese, alguns destes parâmetros podem sofrer modificações significativas por efeito de compactação física e química e do conseqüente rearranjo espacial do arcabouço deposicional, com tendência para diminuição da porosidade original com o soterramento progressivo.

A microscopia quantitativa de rochas porosas, através da análise de imagens digitais obtidas com microscópio petrográfico ou microscópio eletrônico, temse mostrado ferramenta eficiente na determinação das propriedades texturais e petrofísicas. Ela permite o desenvolvimento de rotinas rápidas e precisas de quantificação de determinados parâmetros físicos, como os de porosidade e empacotamento, com grande potencial de aplicação no estudo de reservatórios e aqüíferos.

1 - Universidade de São Paulo, Instituto de Geociências, Programa de Pós-Graduação em Geologia Sedimentar, São Paulo (SP), Brasil.

E-mail: gesicki@usp.br

2 - Universidade de São Paulo, Instituto de Geociências, São Paulo (SP), Brasil.

E-mails: ijsayeg@usp.br, boggiani@usp.br,pcgianni@usp.br

3 - Universidade de São Paulo, Instituto de Geociências, Curso de Graduação em Geologia, São Paulo (SP), Brasil.

E-mail: daicurti@gmail.com 
Este trabalho descreve a aplicação de duas rotinas de análise de imagens digitais de seções delgadas visando a quantificação da porosidade e dos índices de empacotamento segundo proposta de Kahn (1956), no âmbito dos estudos diagenéticos de arenitos de subsuperfície das formações Pirambóia e Botucatu em São Paulo (Gesicki 2007). Estes métodos quantitativos foram aplicados em amostras de calha de um poço de captação de água do Aqüífero Guarani em Barretos, no noroeste paulista, com amostragem representativa das duas unidades.

ANÁLISE DE IMAGENS DIGITAIS O princípio básico da análise de imagens consiste na obtenção de dados quantitativos de parâmetros tridimensionais (por ex., de uma rocha) a partir de medições pontuais, lineares ou areais de imagens bidimensionais (Petruk 1989). A confiabilidade dos dados obtidos e, por extensão, da interpretação deles decorrente, depende de quanto estes dados são precisos e representativos da situação real.

Alguns aspectos fundamentais da eficácia deste tipo de análise residem na escolha do aumento do microscópio e, conseqüentemente, da área do campo de visão microscópica, além do número de imagens a serem analisadas em cada situação.

A imagem microscópica de lâmina pode ser traduzida numa imagem colorida ou numa imagem em tons de cinza, em que cada pixel possui, individualmente, valores específicos de seus componentes óticos. Uma imagem em níveis de cinza possui cores que variam do preto ao branco, em 256 níveis diferentes. A imagem colorida, por sua vez, possui uma gama mais complexa de componentes óticos, representada pelo espectro de cores primárias (componentes RGB), as quais combinadas representam 16 milhões de cores diferentes, e pelos atributos de matiz, intensidade e saturação da imagem, denominados componentes HSI.

Os componentes RGB referem-se à composição da cor pela adição dos elementos espectrais primários vermelho (red), verde (green) e azul (blue). O matiz (hue) representa a cor propriamente dita, tendo por referência o espectro de cores primárias; a saturação (saturation) está relacionada ao grau de diluição da cor pura pela luz branca; a intensidade (intensity) é um atributo não diretamente ligado à cor, mas sim ao brilho, sendo proporcional à soma dos componentes RGB (Crabtree et al. 1984). O sistema de cores em duplo cone da figura 1 exemplifica os componentes da imagem digital colorida.

Sob o microscópio petrográfico, a rocha porosa previamente impregnada com resina colorida é caracterizada, no geral, por arcabouço e cimento predominantemente incolores e espaço poroso tingido de azul. Esta cena microscópica é representada, na imagem digital colorida, por componentes óticos bem distintos ao olho humano, o de poros (azuis) e o de não-poros (em geral, esbranquiçados). A análise de imagens utiliza o contraste dos componentes óticos de uma imagem digital para definir critérios de seleção destes componentes, com o objetivo de quantificá-los, num processo denominado segmentação.
O processo de segmentação O método mais usual para extrair informações de uma imagem digital é através do processo de segmentação, ou seja, subdividir a imagem nos seus componentes óticos (Gonzalez \& Woods 1992) e transformá-la em imagem binária. Em imagens coloridas, o processo de segmentação utiliza os componentes RGB ou HSI, enquanto que em imagens não coloridas, a ferramenta de análise são os níveis de cinza.

O processo de segmentação consiste em adotar determinado critério ótico (nível de cinza, matiz etc.) para identificar regiões da imagem digital com características homogêneas. A imagem segmentada, por sua vez, é transformada em imagem binária, em que a quantificação é mais simples. Um dos métodos de segmentação da imagem mais utilizados é a limiarização (thresholding) de histogramas (Fig. 2), em que se estipulam os limites máximo e mínimo (limiares) de determinado componente da imagem.

Os histogramas de imagens representam a distribuição da freqüência de detecção do componente ótico segundo uma escala linear, que varia de zero a 255 . Por exemplo, intensidade zero representa a percepção do preto ao olho humano, enquanto intensidade 255 representa o branco; a percepção pelo olho humano da cor azul situa-se no intervalo entre 128 e 141 da escala de matiz.

A segmentação definida por limiares depende do caráter polimodal dos histogramas de imagem (Fig. 2), com modas de freqüência bem definidas, representantes do contraste dos componentes óticos. Quanto melhor definido este contraste, maior o sucesso do processamento da imagem digital.

Neste estudo, tanto a quantificação do espaço poroso quanto a determinação dos índices de empacotamento basearam-se na segmentação dos componentes óticos poros e não-poros em histogramas de matiz (Crabtree et al. 1984), uma vez que este componente ótico mostrou distribuição bimodal nítida em quase todas as lâminas analisadas.

MÉTODOS E EQUIPAMENTOS Foram analisadas 37 amostras de fragmentos de calha derivados da perfuração de poço de captação de água subterrânea situado na cidade de Barretos (coordenadas $48^{\circ} 35^{\prime}$ '27,6”'W; $20^{\circ} 31^{\prime} 37,2^{\prime \prime}$ ), disponíveis na litoteca do DAEE, em Araraquara. Neste poço, o intervalo de amostragem de arenitos das formações Pirambóia e Botucatu provém de 820 a $990 \mathrm{~m}$ de profundidade. Os fragmentos de catha foram previamente impregnados com resina azul, de modo a permitir uma melhor distinção do espaço poroso dos fragmentos de rocha ao microscópio.

As seções delgadas foram fotografadas digitalmente e as imagens digitais tratadas e analisadas no computador com o auxílio do programa Leica Qwin 550. A medição da porosidade foi feita através de rotina de análise de imagem adaptada do banco de rotinas do programa Qwin 550, validada pela equipe do Laboratório de Petrografia Sedimentar do IGc-USP. Com relação ao parâmetro empacotamento, a mesma equipe desenvolveu uma rotina de análise de imagem específica para determinação dos índices de densidade 
e proximidade de empacotamento propostos por Kahn (1956). Os procedimentos foram executados com microscópio petrográfico Carl-Zeiss Axioplan 2 e câmera Sony 3CCD acoplada.

As etapas básicas da rotina de análise de imagem, com vistas à quantificação de porosidade em seção delgada, são: (1) aquisiçãa de imagens digitais coloridas de lâminas, com resolução de $512 \times 512$ pixels, armazenadas no formato *.tif; (2) processamento da imagem previamente capturada, com detecção dos pixels correspondentes aos poros (azul), utilizando segmentação do histograma de matiz (Hue); (3) correção automática da imagem binária gerada na etapa anterior, seguida de etapa de edição manual, para correção de eventuais imprecisões da imagem binária; (4) medição da área do binário editado, que corresponde à área dos poros da imagem processada; (5) os valores porcentuais de cada imagem são armazenados em planilha Excel e adota-se como valor de porosidade da lâmina a média aritmética da população de dados de todas as imagens processadas; (6) armazenamento da imagem binária no formato *.tif.

Para a análise dos índices de empacotamento, as etapas básicas da rotina de análise de imagem são: (1) aquisição de imagem digital colorida de lâmina, com resolução de 764x574 pixels; (2) correção automática da imagem digital; (3) processamento da imagem corrigida, com detecção dos pixels correspondentes ao arcabouço (não poro), utilizando segmentação do histograma de matiz (Hue); (4) correção automática da imagem binária gerada na etapa anterior, seguida de etapa de edição manual, para ressaltar o comprimento dos grãos ao longo das transversais x (horizontal) e y (vertical); (5) medição do binário editado anteriormente, no qual os parâmetros "intercept H" e "intercept V" correspondem, respectivamente, ao comprimento total dos grãos na transversal $\mathrm{Y}$ e transversal $\mathrm{X}$. Estes dados são copiados para planilha Excel para o cálculo do índice de densidade ( $\left.\mathrm{IP}_{\mathrm{Kd}}\right)$ de empacotamento de Kahn (1956); (6) armazenamento da imagem colorida e do binário no formato *.tif; (7) etapa de contagem manual dos contatos entre os grãos ao longo das transversais $\mathrm{X}$ e Y. Estes valores são repassados para planilha Excel para o cálculo do índice de proximidade $\left(\mathrm{IP}_{\mathrm{Kp}}\right)$ de empacotamento de Kahn (1956).

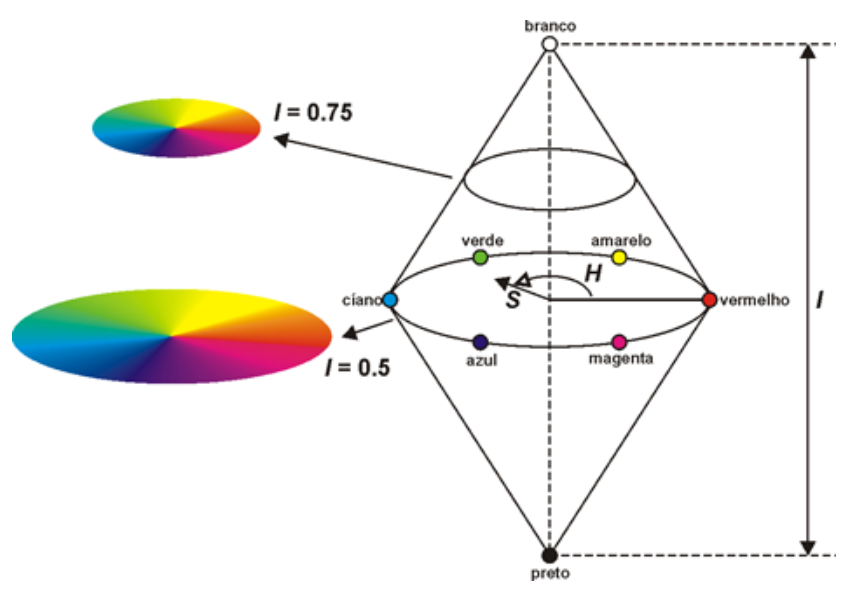

Figura 1 - Sistema de cores em duplo cone, em que estão dispostos os componentes RGB e HSI de uma imagem colorida. O matiz (H) refere-se ao componente de cor na seção circular do cone, que varia entre $0^{\circ}$ (vermelho), $120^{\circ}$ (verde), $240^{\circ}$ (azul) e $360^{\circ}$. A saturação varia de zero (acromático), no centro da seção circular, a 100\% (cor pura), na borda da seção circular. A intensidade varia de zero (preto) a 100\% (branco), e está disposto no eixo de maior comprimento do cone. Proposta de Crabtree et al. (1984).
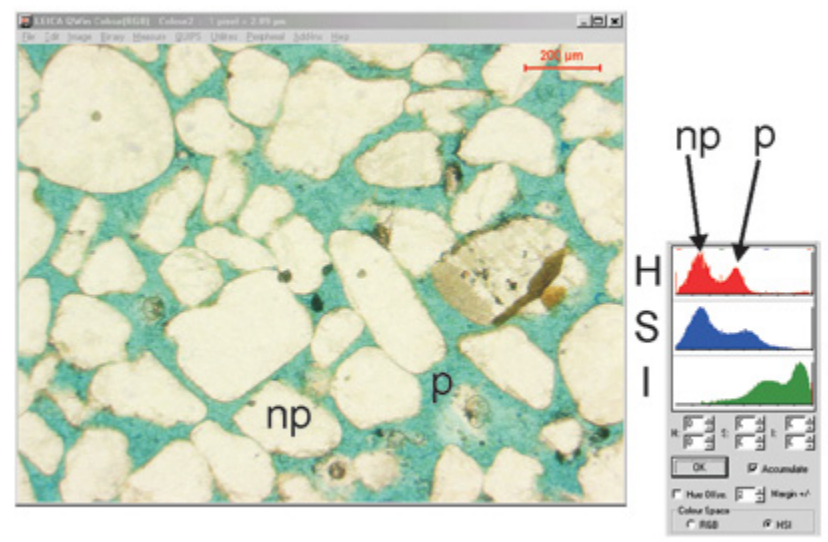

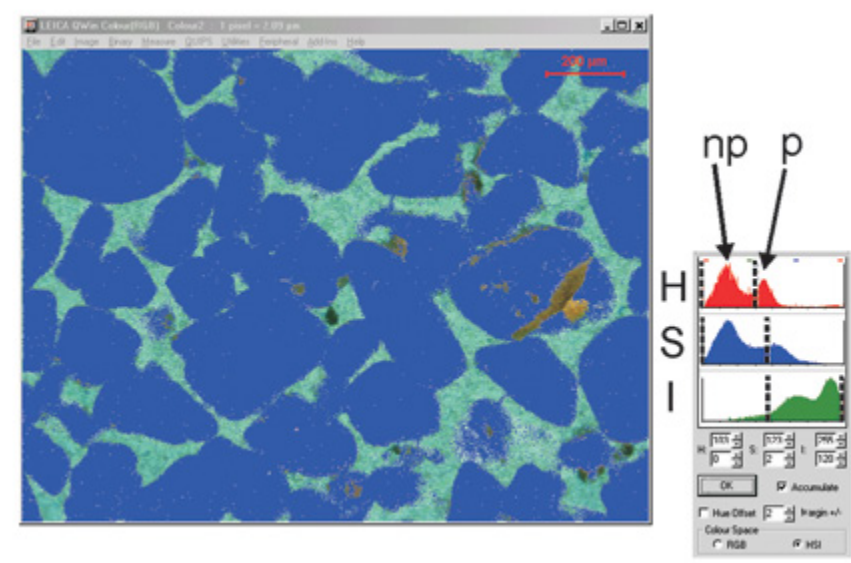

Figura 2 - Método de segmentação por limiares em histogramas dos componentes HSI da imagem colorida. A imagem da esquerda exemplifica a cena microscópica de uma rocha sedimentar com espaço poroso previamente tingido de azul, onde é possível discriminar dois componentes óticos distintos, poros azuis e arcabouço predominantemente branco. O histograma de matiz $(H)$ apresenta bimodalidade nítida dos componentes poros $(p) e$ não poros (np), enquanto nos histogramas de saturação (S) e intensidade (I) a bimodalidade é menos definida. A imagem da direita passou pelo processo de segmentação do arcabouço, com limiares definidos entre zero e 103 do histograma de matiz, que delimitam o componente não poro. 
A escolha do aumento da objetiva levou em conta a granulometria média da rocha. $\mathrm{O}$ aumento de 100x foi utilizado como padrão levando-se em conta que os arenitos das formações Botucatu e Pirambóia apresentam predominantemente granulometria média na fração areia fina e, neste aumento, nota-se uma melhor relação entre resolução e área de cobertura (Erlich et al. 1991). Por outro lado, a distribuição granulométrica bimodal, nas frações areia fina e areia média, é característica comum destes depósitos eólicos. Nesta situação, foi utilizado aumento de 50x (objetiva de 5X) para a captura das imagens, pois notou-se que os desvios padrões eram menores que na situação de maior aumento. No caso da análise de empacotamento, adotou-se como padrão o aumento de 50x, pois a área da imagem mostrou-se representativa, com maior número de grãos do arcabouço se comparado a imagens de aumento maior. A tabela 1 resume as informações das imagens utilizadas neste estudo em termos de resolução e área.

Para obter-se uma análise de porosidade representativa da seção, foram adotados os critérios estabelecidos por Ehrlich et al. (1991), os quais estipulam em dez o número mínimo de imagens a serem capturadas por seção, com recomendação de 25 a 30 imagens como número ideal. Para análise do empacotamento, foram obtidas no mínimo dez imagens por fragmento, porém, em alguns casos, esse número não pôde ser atingido devido à pequena área do fragmento na seção delgada.

DETERMINAÇÃO DE PARÂMETROS TEXTURAIS A determinação de porosidade e do índice de empacotamento de rochas, através de seções delgadas, são procedimentos triviais da análise petrográfica de rochas sedimentares e amplamente utilizados para a caracterização geológica de reservatórios.

A porosidade em uma rocha sedimentar pode ser primária, determinada pelo espaço original entre os grãos logo após a deposição, ou secundária, formada ao longo da diagênese, através da dissolução dos grãos, cimentos e matrizes. O empacotamento diz respeito ao arranjo dos grãos entre si, dentro de um arcabouço mais fechado ou mais aberto, dependendo do histórico de soterramento das rochas na diagênese. Quanto maior o soterramento, maior a pressão efetiva entre os grãos, o que favorece modificações de caráter físico, como o rearranjo espacial dos constituintes deposicionais.

Existe relação entre o tipo de empacotamento e a escala nominal de porosidade intergranular, como reconhecido inicialmente por Graton \& Fraser (1935). $\mathrm{O}$ arranjo tridimensional dos grãos teoricamente varia de cúbico, tipo de empacotamento mais aberto, onde a porosidade teórica é de $47 \%$, a romboédrico, empacotamento mais fechado, com porosidade teórica de $26 \%$ (Fig. 3). Essa relação aparente pode não existir se o arenito, por exemplo, tiver sido submetido a cimentação pervasiva em estágio diagenético precoce, e exibir empacotamento aberto e porosidade desprezível. Outra situação que foge aos modelos teóricos é a polimodalidade da distribuição granulométrica do arcabouço, que favorece o arranjo mais fechado e porosidade reduzida, uma vez que os grãos mais finos ocupam os interstícios dos grãos mais grossos.

Tanto a porosidade quanto o empacotamento de uma rocha são parâmetros tridimensionais: o primeiro expressa o percentual de volume de vazios e o segundo refere-se ao arranjo espacial de grãos. A quantificação

Tabela 1 - Especificações das imagens digitais analisadas.

\begin{tabular}{|c|c|c|c|c|c|}
\hline Tipo de análise & $\begin{array}{c}\text { Granulação média da } \\
\text { amostra }\end{array}$ & Aumento & $\begin{array}{l}\text { Resolução da } \\
\text { imagem }\end{array}$ & Área da imagem & Número de imagens \\
\hline \multirow{2}{*}{ Porosidade } & areia fina & $100 \mathrm{X}$ & $512 \times 512$ pixel & $0,281 \mathrm{~mm}^{2}$ & \multirow{2}{*}{ mín. 10 , máx. 30} \\
\hline & areia média ou bimodal & $50 X$ & $512 \times 512$ pixel & $1,14 \mathrm{~mm}^{2}$ & \\
\hline Empacotamento & $\begin{array}{c}\text { areia fina, areia média ou } \\
\text { bimodal }\end{array}$ & $50 \mathrm{X}$ & $764 \times 574$ pixel & $1,91 \mathrm{~mm}^{2}$ & mín. 10 \\
\hline
\end{tabular}

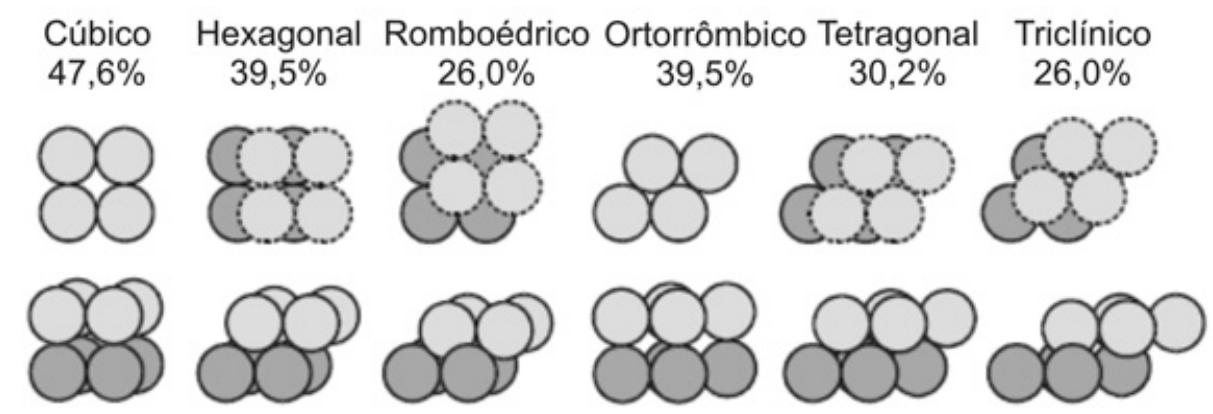

Figura 3 - Tipos de empacotamento e respectivos valores máximos de porosidade segundo arranjo teórico de esferas perfeitas. Extraído de Glover (2000). 
destes parâmetros a partir de dados unidimensionais ou bidimensionais depende da adoção da premissa básica de extrapolação do valor medido para a terceira dimensão, corolário do princípio estereológico, também denominado transfer function (Erlich et al. 1984).

A quantificação da porosidade em seção delgada pode ser obtida por análise modal ou análise de imagem, com cálculo percentual simples do total de pontos contados como poros ou da área detectada como tal em relação à população total de dados. Por outro lado, o empacotamento é um parâmetro difícil de ser traduzido em termos numéricos, independentemente da dimensão analisada.

Kahn (1956) propôs dois métodos unidimensionais de cálculo do índice de empacotamento de arenitos, através da medição de parâmetros ao longo de uma transversal imaginária (linha horizontal do retículo), em imagem de seções delgadas (Fig. 4). O índice de densidade de empacotamento ( $\mathrm{IP}_{\mathrm{Kd}}$ ) foi definido como a razão entre o comprimento dos grãos do arcabouço ao longo desta transversal e o comprimento total da mesma, sendo os valores expressos em porcentagem. Quanto ao índice de proximidade de empacotamento $\left(\mathrm{IP}_{\mathrm{Kp}}\right)$, proposto pelo autor, a medida obtida resulta da razão entre a soma do número de contatos entre grãos, ao longo de uma transversal, e o número total de grãos interceptados por ela, sendo o valor expresso também em porcentagem. Quanto maiores os valores percentuais dos índices de empacotamento de Kahn (1956), mais fechado se encontra o arcabouço da rocha.

RESULTADOS OBTIDOS A relação das amostras analisadas e os resultados analíticos estão relacionados nas tabelas 2, 3 e 4 .

Os arenitos das formações Pirambóia e Botucatu são caracterizados por arenitos finos a médios, em geral com seleção granulométrica boa a moderada, arcabouço de grãos arrendondados e subarredondados, associados a processos deposicionais predominantemente eólicos e secundariamente subaquosos.

Os resultados de porosidade obtidos referem-se à macroporosidade total da cena microscópica, uma vez que não foram discriminados os tipos de porosidade durante a análise, por exemplo se intergranular ou intraconstituinte. A porosidade intergranular medida em imagens digitais geralmente representa a porosidade efetiva, ou seja, referente à rede de poros interconectados. A porosidade intraconstituinte reconhecida neste estudo é principalmente alveolar e, em menor proporção, móldica em grãos do arcabouço quimicamente instáveis. A porosidade criada por lixiviação de grãos durante a diagênese é tipicamente secundária, sensu Schmidt \& McDonald (1979), e pouco contribui para o aumento da porosidade efetiva da rocha por estar situada em poros não conectados.

A porosidade das amostras de calha do poço de Barretos é alta, em média $28,47 \%$ nos fragmentos de arenito da Formação Botucatu (Tab. 3). Os fragmentos de rocha da Formação Pirambóia Superior apresentam baixa porosidade, em média $3,23 \%$, devido à obstrução do espaço intergranular por cimento carbonático. Porém, em amostras em que não há obstrução por cimento carbonático, a porosidade é muito elevada, cerca de $39,55 \%$, em média.

As amostras analisadas apresentam empacotamento aberto, com valores médios do índice de densidade de empacotamento (IP ${ }_{\text {Kd }}$ ) variando de $58,9 \%$ a $81,7 \%$ e índices de proximidade de empacotamento $\left(\mathrm{IP}_{\mathrm{Kp}}\right)$ menores que $25 \%$ (Tab. 4).

Com relação à análise de porosidade, nota-se que os fragmentos de calha da Formação Pirambóia apresentam porosidade superior aos fragmentos da Formação Botucatu no poço de Barretos. A Formação Bo-

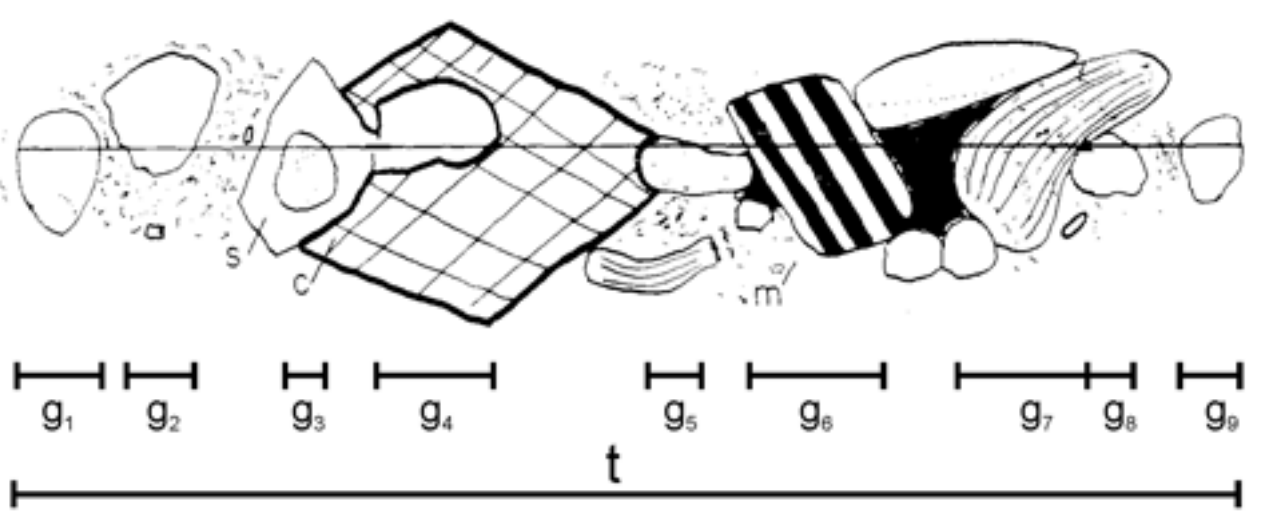

Figura 4 - Representação esquemática do cálculo dos índices de densidade e proximidade de empacotamento de Kahn (1956). O índice de densidade de empacotamento corresponde à razão entre a soma dos comprimentos dos grãos (gl a g9), ao longo da transversal $(t)$, e o comprimento total de $t$. $O$ indice de proximidade de empacotamento é igual à razão entre o número de contatos grão-a-grão na transversal (um contato) $e$ o número de grãos interceptados por ela (9 grãos). Neste exemplo o $I P_{K d}=59,14 \%$ e o $I P_{K p}=11,11 \%$. Legenda: c: cimento carbonático, s: cimento de quartzo, m: matriz, fundo preto: poro, triângulo: contato intergranular. Extraído de Kahn (1956). 
Tabela 2 - Relação das amostras analisadas. P: análise de porosidade, E: análise dos índices de empacotamento.

\begin{tabular}{|c|c|c|c|c|c|c|c|c|}
\hline \multirow[t]{2}{*}{ Amostra } & \multirow[t]{2}{*}{ Prof. (m) } & \multirow{2}{*}{$\begin{array}{c}\text { Fragm. } \\
\left(\mathrm{n}^{\mathrm{o}}\right)\end{array}$} & \multirow[t]{2}{*}{ Unidade Estratigráfica } & \multirow[t]{2}{*}{ Análise } & \multicolumn{2}{|c|}{ Aumento } & \multirow{2}{*}{$\begin{array}{c}\text { № de } \\
\text { imagens (P) }\end{array}$} & \multirow{2}{*}{$\begin{array}{c}\text { № de } \\
\text { imagens (E) }\end{array}$} \\
\hline & & & & & $\mathrm{P}$ & $\mathrm{E}$ & & \\
\hline \multirow{2}{*}{ BA03a } & \multirow{2}{*}{824} & 1 & \multirow{2}{*}{ Fm. Botucatu } & $\mathrm{P}$ & $10 \mathrm{x}$ & - & 22 & - \\
\hline & & 4 & & $\mathrm{P}, \mathrm{E}$ & $10 \mathrm{x}$ & $5 \mathrm{x}$ & 30 & 15 \\
\hline $\mathrm{BA} 03 \mathrm{~b}$ & 830 & 4 & Fm. Botucatu & $\mathrm{P}, \mathrm{E}$ & $10 \mathrm{x}$ & $5 \mathrm{x}$ & 30 & 13 \\
\hline \multirow{2}{*}{ BA03c } & \multirow{2}{*}{834} & \multirow{2}{*}{8} & \multirow{2}{*}{ Fm. Botucatu } & \multirow{2}{*}{$\mathrm{P}, \mathrm{E}$} & $10 \mathrm{x}$ & \multirow{2}{*}{$5 \mathrm{x}$} & 30 & \multirow{2}{*}{12} \\
\hline & & & & & $5 \mathrm{x}$ & & 12 & \\
\hline \multirow{2}{*}{ BA03d } & \multirow{2}{*}{844} & 5 & \multirow{2}{*}{ Fm. Botucatu } & $\mathrm{P}, \mathrm{E}$ & $10 \mathrm{x}$ & $5 \mathrm{x}$ & 30 & 10 \\
\hline & & 6 & & $\mathrm{P}, \mathrm{E}$ & $5 \mathrm{x}$ & $5 \mathrm{x}$ & 16 & 09 \\
\hline BA03e & 846 & 5 & Fm. Botucatu & $\mathrm{P}, \mathrm{E}$ & $10 \mathrm{x}$ & $5 \mathrm{x}$ & 30 & 09 \\
\hline \multirow{2}{*}{ BA03f } & \multirow{2}{*}{852} & 2 & \multirow{2}{*}{ Fm. Botucatu } & $\mathrm{P}, \mathrm{E}$ & $10 \mathrm{x}$ & $5 \mathrm{x}$ & 30 & 15 \\
\hline & & 6 & & $\mathrm{P}$ & $10 \mathrm{x}$ & - & 30 & - \\
\hline BA03g & 876 & 1 & Fm Potucatu & $\mathrm{P}, \mathrm{E}$ & $10 \mathrm{x}$ & $5 \mathrm{x}$ & 30 & 10 \\
\hline & $8 / 6$ & 3 & Fm. Botucatu & $\mathrm{P}, \mathrm{E}$ & $10 \mathrm{x}$ & $5 \mathrm{x}$ & 30 & 11 \\
\hline 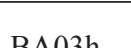 & 880 & 3 & Fm Rotucotu & $\mathrm{P}, \mathrm{E}$ & $10 \mathrm{x}$ & $5 \mathrm{x}$ & 30 & 13 \\
\hline BAOSn & 880 & 1 & Fm. Botucatu & $\mathrm{E}$ & - & $5 \mathrm{x}$ & - & 12 \\
\hline & & 3 & & $\mathrm{P}, \mathrm{E}$ & $10 \mathrm{x}$ & $5 \mathrm{x}$ & 30 & 14 \\
\hline BA03j & 886 & 8 & Fm. Botucatu & $\mathrm{P}, \mathrm{E}$ & $10 \mathrm{x}$ & $5 \mathrm{x}$ & 30 & 11 \\
\hline & & 10 & & $\mathrm{P}$ & $10 \mathrm{x}$ & - & 30 & - \\
\hline BA03k & 890 & 2 & Fm. Botucatu & $\mathrm{P}, \mathrm{E}$ & $10 \mathrm{x}$ & $5 \mathrm{x}$ & 30 & 12 \\
\hline BA031 & 900 & 2 & Fm. Pirambóia Superior & $\mathrm{P}, \mathrm{E}$ & $5 x$ & $5 \mathrm{x}$ & 13 & 13 \\
\hline DAOSI & 900 & 7 & Fm. Botucatu & $\mathrm{P}, \mathrm{E}$ & $10 \mathrm{x}$ & $5 \mathrm{x}$ & 30 & 12 \\
\hline $\mathrm{BA} 03 \mathrm{~m}$ & 904 & 6 & Fm Botucatu & $\mathrm{P}, \mathrm{E}$ & $10 \mathrm{x}$ & $5 \mathrm{x}$ & 30 & 14 \\
\hline BAU3m & 904 & 2 & Fm. Botucatu & $\mathrm{P}$ & $10 \mathrm{x}$ & - & 30 & - \\
\hline $\mathrm{BA} 03 \mathrm{n}$ & 906 & 6 & Fm. Pirambóia Superior & $\mathrm{P}, \mathrm{E}$ & $5 x$ & $5 \mathrm{x}$ & 21 & 7 \\
\hline DAOSII & 900 & 3 & Fm. Botucatu & $\mathrm{P}, \mathrm{E}$ & $10 \mathrm{x}$ & $5 \mathrm{x}$ & 30 & 13 \\
\hline BA03o & 008 & 5 & Fm. Pirambóia Superior & $\mathrm{P}, \mathrm{E}$ & $10 \mathrm{x}$ & $5 \mathrm{x}$ & 30 & 12 \\
\hline & 908 & 3 & Fm. Botucatu & $\mathrm{P}, \mathrm{E}$ & $10 \mathrm{x}$ & $5 \mathrm{x}$ & 30 & 15 \\
\hline BA03n $>>2>0$ & 010 & 5 & Fm. Pirambóia Superior & $\mathrm{P}, \mathrm{E}$ & $5 \mathrm{x}$ & $5 \mathrm{x}$ & 13 & 13 \\
\hline BAUSP & 910 & 4 & Fm. Botucatu & $\mathrm{P}, \mathrm{E}$ & $10 \mathrm{x}$ & $5 \mathrm{x}$ & 30 & 13 \\
\hline BA03a & 014 & 2 & Fm Piramhóin Sunerior & $\mathrm{P}, \mathrm{E}$ & $10 \mathrm{x}$ & $5 \mathrm{x}$ & 28 & 9 \\
\hline DAOSq & 914 & 7 & Fm. Piramboia superior & $\mathrm{E}$ & - & $5 \mathrm{x}$ & - & 7 \\
\hline $\mathrm{BA} 03 \mathrm{r}$ & 918 & 4 & Fm. Pirambóia Superior & $\mathrm{P}, \mathrm{E}$ & $10 \mathrm{x}$ & $5 \mathrm{x}$ & 30 & 16 \\
\hline DAOSI & 910 & 1 & Fm. Botucatu & $\mathrm{P}, \mathrm{E}$ & $10 \mathrm{x}$ & $5 \mathrm{x}$ & 30 & 17 \\
\hline $\mathrm{BA} 03 \mathrm{~s}+2 \mathrm{C}-\mathrm{s}$ & 922 & 1 & Fm Piramhói Sunerior & $\mathrm{P}, \mathrm{E}$ & $10 \mathrm{x}$ & $5 \mathrm{x}$ & 27 & 07 \\
\hline BAOJS & 922 & 7 & Fm. Piramooid superior & $\mathrm{P}, \mathrm{E}$ & $10 \mathrm{x}$ & $5 \mathrm{x}$ & 27 & 07 \\
\hline $\mathrm{BA} 037$ & 054 & 2 & Fm Piramhóia & $\mathrm{P}$ & $10 \mathrm{x}$ & - & 30 & - \\
\hline DAOSZ & 9054 & 8 & Fin. Piramoora & $\mathrm{P}$ & $10 \mathrm{x}$ & - & 30 & - \\
\hline 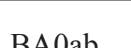 & 964 & 2 & Fm Piramhóia & P & $10 \mathrm{x}$ & - & 30 & - \\
\hline BAUaD & 904 & 2 & rm. Pirambora & $P^{P}$ & $5 \mathrm{x}$ & - & 13 & - \\
\hline BA03ac & 968 & 3 & Fm. Pirambóia & $\mathrm{P}$ & $10 \mathrm{x}$ & - & 27 & - \\
\hline
\end{tabular}

tucatu apresenta porosidade média variando de $20,0, \%$ a $36,3 \%$ e a Formação Pirambóia de $35,6 \%$ a $45,7 \%$. Nos fragmentos da Formação Pirambóia, o maior valor médio de porosidade aproxima-se dos valores de porosidade original medidos em areias eólicas inconsolidadas (Atkins \& McBride 1992). No entanto, estes valores altos na verdade estão associados à presença de volume significativo de porosidade secundária intragranular, que em algumas imagens chega a constituir quase $10 \%$ do volume total de poros da imagem (Fig. 5).

\section{PROBLEMAS DECORRENTES DA ANÁLISE DE}

IMAGENS O limite de detecção da porosidade em seções delgadas, através da análise de imagens digitais, depende diretamente da resolução da imagem capturada (tamanho do pixel), que por sua vez depende do au- 
Tabela 3 - Resultados de porosidade através da análise de imagens digitais.

\begin{tabular}{|c|c|c|c|c|c|}
\hline Amostra & $\begin{array}{c}\text { Fragm. } \\
\left(\mathrm{n}^{\mathrm{o}}\right)\end{array}$ & $\begin{array}{c}\text { Média } \\
(\%)\end{array}$ & $\begin{array}{l}\text { Desvio } \\
\text { Padrão }\end{array}$ & $\begin{array}{l}\text { Máximo } \\
(\%)\end{array}$ & $\begin{array}{c}\text { Mínimo } \\
(\%)\end{array}$ \\
\hline \multirow{2}{*}{ BA-03a } & 1 & 30,77 & 5,61 & 41,79 & 22,03 \\
\hline & 4 & 29,70 & 5,36 & 40,17 & 17,81 \\
\hline BA-03b & 4 & 28,53 & 6,29 & 44,74 & 19,22 \\
\hline BA-03c & 8 & 31,66 & 2,40 & 35,31 & 27,43 \\
\hline \multirow{2}{*}{ BA-03d } & 5 & 24,69 & 4,51 & 33,34 & 16,31 \\
\hline & 6 & 25,62 & 3,29 & 31,78 & 20,31 \\
\hline BA-03e & 5 & 26,26 & 4,03 & 36,69 & 19,24 \\
\hline \multirow{2}{*}{ BA-03f } & 2 & 31,86 & 5,60 & 44,85 & 20,12 \\
\hline & 6 & 36,26 & 4,08 & 44,11 & 26,39 \\
\hline \multirow{2}{*}{ BA- $03 \mathrm{~g}$} & 1 & 28,21 & 5,75 & 41,72 & 17,60 \\
\hline & 3 & 28,59 & 8,41 & 50,91 & 13,82 \\
\hline BA-03h & 3 & 32,42 & 5,38 & 46,9 & 22,75 \\
\hline BA-03j & 3 & 26,57 & 3,87 & 35,75 & 17,80 \\
\hline \multirow[b]{2}{*}{ BA- $03 \mathrm{c}$} & 8 & 27,88 & 6,18 & 41,18 & 18,39 \\
\hline & 10 & 27,43 & 4,30 & 36,48 & 17,74 \\
\hline BA-03k & 2 & 20,52 & 4,94 & 30,95 & 10,15 \\
\hline BA-031 & 2 & 8,60 & 6,07 & 22,89 & 1,24 \\
\hline BA-03e & 7 & 27,44 & 6,34 & 42,3 & 12,51 \\
\hline \multirow{2}{*}{ BA-03m } & 6 & 27,59 & 3,27 & 33,6 & 21,81 \\
\hline & 2 & 32,57 & 5,48 & 42,49 & 20,82 \\
\hline \multirow{2}{*}{ BA- $03 n$} & 6 & 4,53 & 3,95 & 13,79 & 0,69 \\
\hline & 3 & 22,37 & 3,69 & 34,04 & 16,12 \\
\hline \multirow{2}{*}{ BA-03o } & 5 & 1,04 & 2,53 & 11,96 & 0,00 \\
\hline & 3 & 26,18 & 7,57 & 42,91 & 10,97 \\
\hline \multirow{2}{*}{ BA- $03 p$} & 5 & 8,21 & 8,99 & 28,08 & 0,14 \\
\hline & 4 & 26,56 & 4,59 & 35,86 & 17,38 \\
\hline BA-03q & 2 & 1,14 & 2,27 & 11,17 & 0,00 \\
\hline BA-03r & 4 & 1,96 & 3,31 & 11,71 & 0,00 \\
\hline BA-03k & 1 & 35,14 & 4,38 & 44,14 & 27,56 \\
\hline BA-03s & 1 & 0,06 & 0,16 & 0,66 & 0,00 \\
\hline BA-03e & 7 & 0,32 & 0,96 & 4,76 & 0,00 \\
\hline \multirow{2}{*}{ BA- $03 z$} & 2 & 37,38 & 7,32 & 50,44 & 24,65 \\
\hline & 8 & 42,38 & 7,01 & 54,84 & 26,7 \\
\hline BA-03ab & 2 & 42,87 & 4,35 & 50,29 & 35,11 \\
\hline BA-03ac & 3 & 35,64 & 6,33 & 50,57 & 24,65 \\
\hline
\end{tabular}

mento do microscópio. Este método analítico é impreciso para deteç̧ão de microporosidade, ou seja, aquela contida nas imediações dos contatos grão a grão ou dispersa na fração fina do cimento ou matriz, que em geral possui dimensões da ordem de alguns micrômetros. Arenitos com conteúdo de cimento de argilominerais superior a $10 \%$ ou wackes (arenitos ricos em matriz) não apresentam resultados confiáveis de medição de porosidade através da análise de imagens digitais.

Outra fonte de imprecisão da análise de porosi-
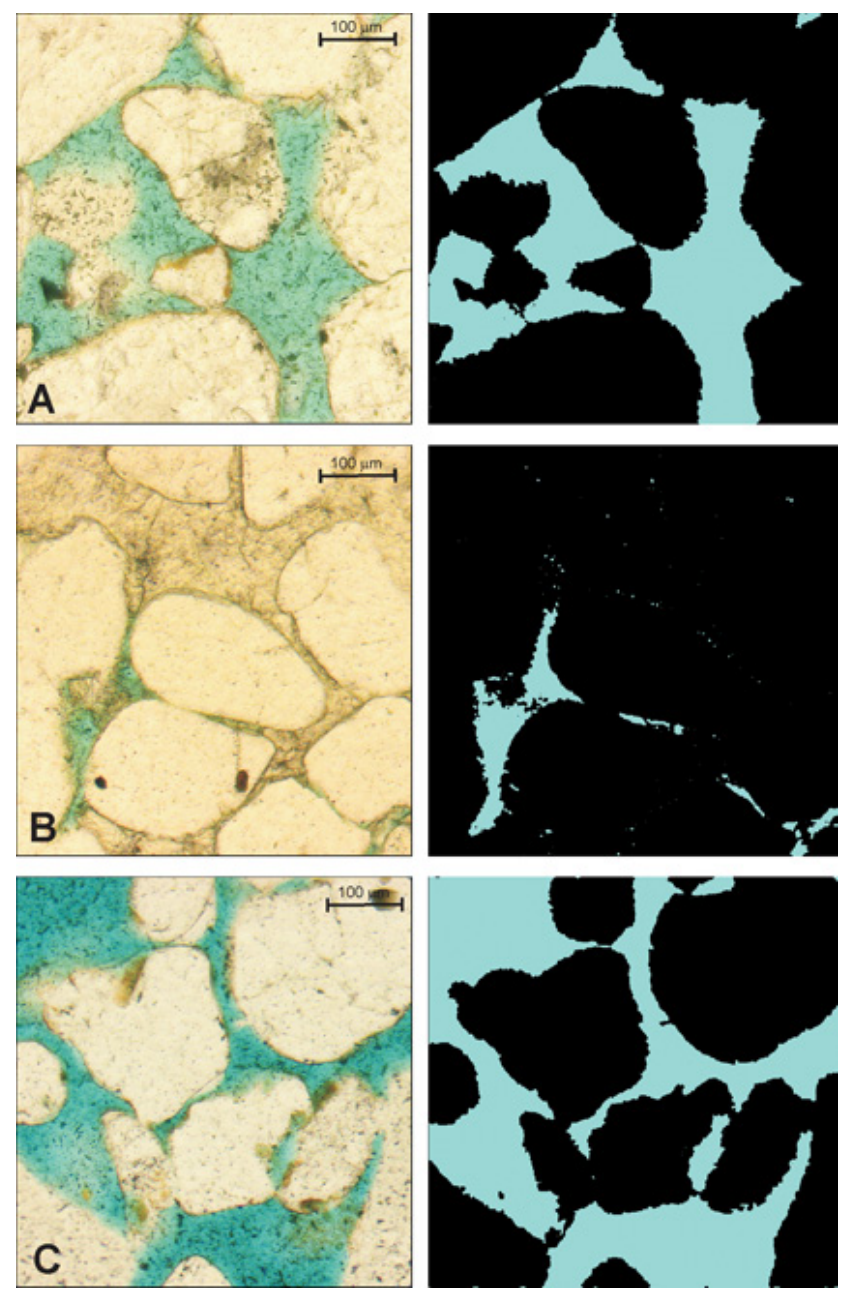

Figura 5 - Exemplos de análise de porosidade de lâmina. A) Formação Botucatu, $876 \mathrm{~m}$, porosidade 30,13\%. B) Formação Pirambóia Superior, 914 m, porosidade 9,2\%. C) Formação Pirambóia, $968 \mathrm{~m}$, porosidade $40,25 \%$.

dade de lâmina refere-se à eventual distribuição homogênea dos histogramas de componentes óticos, do tipo unimodal ou bimodal mal definido. Histograma com distribuição unimodal significa que a imagem não possui contraste da escala de variação de determinado componente ótico. No caso do histograma de matiz, que em geral apresenta distribuição bimodal nítida entre poros e não poros numa imagem de rocha previamente impregnada com resina azul, a bimodalidade mal definida costuma estar associada à alta razão entre o perímetro do poro e a sua área propriamente dita. Poros com bordas de contorno muito irregular apresentam grande quantidade de pontos ou pixels de borda (edge points), os quais chegam a compor uma fração significativa da imagem (Crabtree et al. 1984). Os pontos de borda de poro constituem interface em forma de cunha entre o poro e o arcabouço da rocha (não poro), com sobreposição de um pelo outro. $\mathrm{O}$ efeito ótico da sobreposição do poro pelo não poro, ou vice-versa, resulta numa mistura ótica de cada componente, fazendo com que um alto núme- 
Tabela 4 - Resultados dos índices de empacotamento de Kahn (1956) através de análise de imagens digitais.

\begin{tabular}{|c|c|c|c|c|c|c|c|c|c|}
\hline \multirow{2}{*}{ Amostra } & \multirow{2}{*}{$\begin{array}{c}\text { Fragm. } \\
\left(\mathrm{n}^{\mathrm{o}}\right)\end{array}$} & \multicolumn{4}{|c|}{ densidade de empacotamento } & \multicolumn{4}{|c|}{ proximidade de empacotamento } \\
\hline & & $\begin{array}{c}\text { Média } \\
(\%)\end{array}$ & $\begin{array}{l}\text { Desvio } \\
\text { Padrão }\end{array}$ & $\begin{array}{c}\text { Máximo } \\
(\%)\end{array}$ & $\begin{array}{c}\text { Mínimo } \\
(\%)\end{array}$ & Média (\%) & $\begin{array}{l}\text { Desvio } \\
\text { Padrão }\end{array}$ & $\begin{array}{c}\text { Máximo } \\
(\%)\end{array}$ & Mínimo (\%) \\
\hline BA-03a & 4 & 75,70 & 7,93 & 86,24 & 57,62 & 20,58 & 11,34 & 36,84 & 0,00 \\
\hline BA-03b & 4 & 81,20 & 5,59 & 90,50 & 69,35 & 21,44 & 8,77 & 33,33 & 7,14 \\
\hline BA-03c & 8 & 76,81 & 6,30 & 85,72 & 65,17 & 18,21 & 5,25 & 27,78 & 7,14 \\
\hline \multirow{2}{*}{ BA-03d } & 5 & 76,00 & 5,58 & 87,22 & 69,80 & 11,22 & 7,18 & 22,22 & 0,00 \\
\hline & 6 & 78,02 & 8,62 & 90,06 & 64,64 & 6,72 & 10,94 & 33,33 & 0,00 \\
\hline BA-03e & 5 & 74,44 & 12,44 & 84,23 & 42,74 & 20,55 & 5,45 & 31,82 & 13,64 \\
\hline BA-03f & 2 & 72,40 & 4,37 & 77,87 & 64,27 & 12,20 & 8,58 & 28,00 & 0,00 \\
\hline \multirow{2}{*}{ BA-03g } & 1 & 81,71 & 5,53 & 89,38 & 71,45 & 24,74 & 6,78 & 36,36 & 15,00 \\
\hline & 3 & 76,65 & 6,77 & 85,42 & 63,15 & 12,35 & 6,54 & 20,00 & 0,00 \\
\hline \multirow{2}{*}{ BA-03h } & 3 & 74,66 & 6,40 & 86,09 & 67,19 & 17,16 & 8,72 & 33,33 & 5,56 \\
\hline & 1 & 76,67 & 6,03 & 86,99 & 67,41 & 14,02 & 9,18 & 33,33 & 0,00 \\
\hline \multirow{2}{*}{ BA- $03 j$} & 3 & 76,66 & 5,32 & 86,99 & 64,49 & 21,18 & 8,77 & 32,14 & 5,26 \\
\hline & 8 & 78,36 & 7,26 & 86,54 & 66,29 & 21,46 & 11,65 & 40,00 & 4,76 \\
\hline BA-03k & 2 & 64,82 & 5,79 & 75,56 & 53,58 & 14,85 & 4,76 & 25,93 & 8,00 \\
\hline \multirow{2}{*}{ BA-031 } & 2 & 64,97 & 10,25 & 82,13 & 51,56 & 9,95 & 11,23 & 30,00 & 0,00 \\
\hline & 7 & 75,06 & 5,06 & 85,80 & 66,59 & 12,72 & 8,17 & 25,00 & 0,00 \\
\hline BA- $03 m$ & 6 & 65,12 & 10,39 & 79,67 & 34,83 & 15,97 & 9,31 & 38,46 & 0,00 \\
\hline \multirow{2}{*}{ BA-03n } & 6 & 65,02 & 13,12 & 79,67 & 46,11 & 4,82 & 5,21 & 11,11 & 0,00 \\
\hline & 3 & 78,63 & 4,10 & 86,09 & 71,37 & 24,04 & 5,59 & 33,33 & 15,79 \\
\hline \multirow{2}{*}{ BA-03o } & 5 & 61,06 & 15,61 & 80,86 & 39,53 & 13,40 & 8,92 & 35,29 & 0,00 \\
\hline & 3 & 81,56 & 6,10 & 89,68 & 69,35 & 17,55 & 9,06 & 32,00 & 6,67 \\
\hline \multirow{2}{*}{ BA-03p } & 5 & 76,69 & 10,83 & 94,99 & 53,51 & 11,06 & 10,94 & 36,36 & 0,00 \\
\hline & 4 & 75,99 & 4,83 & 85,27 & 67,56 & 19,80 & 6,54 & 33,33 & 7,69 \\
\hline \multirow{2}{*}{ BA-03q } & 2 & 58,96 & 10,28 & 75,86 & 40,43 & 8,66 & 5,98 & 16,67 & 0,00 \\
\hline & 7 & 67,70 & 12,52 & 83,85 & 52,76 & 12,96 & 8,43 & 31,25 & 7,69 \\
\hline \multirow{2}{*}{ BA- $03 r$} & 4 & 67,13 & 8,54 & 81,76 & 51,64 & 7,15 & 6,71 & 20,00 & 0,00 \\
\hline & 1 & 70,95 & 6,25 & 82,43 & 58,07 & 11,42 & 6,66 & 20,83 & 0,00 \\
\hline \multirow{2}{*}{ BA-03s } & 1 & 66,18 & 7,34 & 76,15 & 55,23 & 9,13 & 5,42 & 15,00 & 0,00 \\
\hline & 7 & 62,73 & 8,49 & 70,92 & 44,31 & 4,80 & 3,33 & 7,69 & 0,00 \\
\hline
\end{tabular}

ro de pontos de borda interfira na definição das modas de um histograma, suavizando os picos. Esse problema foi denominado efeito cantoneira (shelving effect) por Crabtree et al. (1984). A detecção das bordas de poro constitui, portanto, a fonte principal de imprecisão no processo de segmentação por limiares, pois diferentes operadores podem interpretar uma mesma imagem de maneiras distintas, e os resultados quantitativos finais serem significativamente diferentes.

Crabtree et al. (1984) já haviam chamado a atenção quanto à correta detecção do componente poros du- rante o processo de segmentação de imagens de lâmina. Estes autores apontam que os grãos do arcabouço geralmente são caracterizados por baixa saturação, alta intensidade e baixos valores de matiz, ao passo que os poros, por contraste, apresentam valores intermediários de matiz, saturação e intensidade. As bordas de poro tendem a apresentar baixos valores de saturação (poro sobrepondo grão) enquanto que os falsos poros (grão sobrepondo poro) apresentam também alta intensidade (Tab. 5). Desta forma, a detecção mais precisa da porosidade deve excluir valores de intensidade menores que 7\% (preto) 
Tabela 5 - Características dos componentes óticos numa imagem de lâmina.

\begin{tabular}{|c|c|c|c|c|}
\hline Componente & Percepção do olho humano & Matiz & Saturação & Intensidade \\
\hline PORO & Azul & $\begin{array}{c}\text { Intermediário } \\
\text { (entre verde e azul) }\end{array}$ & $\begin{array}{c}\text { Intermediária } \\
(\mathrm{em} \text { geral }>30 \%)\end{array}$ & $\begin{array}{c}\text { Variável } \\
\text { (entre } 7 \% \text { e } 75 \%) \\
\end{array}$ \\
\hline NÃO PORO & "Incolor" & $\begin{array}{c}\text { Baixo } \\
\text { (entre vermelho e verde) }\end{array}$ & $\begin{array}{c}\text { Baixa } \\
(\mathrm{em} \text { geral }<30 \%)\end{array}$ & $\begin{array}{c}\text { Alta } \\
(\mathrm{em} \mathrm{geral}>75 \%) \\
\end{array}$ \\
\hline $\begin{array}{l}\text { BORDA DE PORO } \\
\text { (poro sobrepõe grão) }\end{array}$ & Azulado & $\begin{array}{c}\text { Variável } \\
\text { (entre as modas de } \\
\text { freqüência) }\end{array}$ & $\begin{array}{c}\text { Baixa a } \\
\text { intermediária }\end{array}$ & $\begin{array}{c}\text { Variável } \\
\text { (entre } 7 \% \text { e } 75 \% \text { ) }\end{array}$ \\
\hline $\begin{array}{c}\text { FALSO PORO } \\
\text { (grão sobrepõe poro) }\end{array}$ & Azulado & $\begin{array}{c}\text { Variável } \\
\text { (entre as modas de } \\
\text { freqüência) }\end{array}$ & $\begin{array}{c}\text { Baixa a } \\
\text { intermediária }\end{array}$ & $\begin{array}{c}\text { Alta } \\
(\mathrm{em} \text { geral }>75 \%)\end{array}$ \\
\hline
\end{tabular}

e maiores que $75 \%$ (branco) e desconsiderar valores de saturação menores que 5\% (Crabtree et al. 1984).

CONSIDERAÇÕES FINAIS A análise de imagem de seções delgadas é um procedimento viável e preciso para quantificação de porosidade em lâmina e do índice de empacotamento de arenitos eólicos, desde que baseada em critérios analíticos bem estabelecidos. O processamento de cada imagem, individualmente, é rápido, de até 3 minutos. O que torna o processo relativamente demorado é o elevado número de imagens a serem capturadas exigido para a representatividade da análise: 30 imagens, para análise de porosidade, e de no mínimo 10, para análise de empacotamento.

Ambas rotinas de análise de imagem passaram por processo de validação. Neste processo, uma mesma imagem foi analisada seis vezes seguidas por cinco operadores diferentes e os resultados analíticos foram comparados entre si através de testes estatísticos de si- milaridade. Através dessa comparação, as duas rotinas de análise de imagem foram consideradas válidas como método de análise.

Os fragmentos de calha das formações Pirambóia e Botucatu, no poço de Barretos, apresentam porosidades altas, com médias de $39,55 \%$ e $28,47 \%$, respectivamente. $\mathrm{O}$ arcabouço de amostras de ambas unidades é aberto, com valores de densidade de empacotamento variando de $59 \%$ a $82 \%$ e de proximidade de empacotamento inferior a $25 \%$.

Agradecimentos Os autores agradecem à FAPESP, pelo financiamento do projeto de pesquisa (processo 03/08911-0), ao CNPq, pela concessão de bolsas de Iniciação Científica à co-autora DKC, e à CAPES, pela concessão de bolsa de doutoramento à primeira autora. Agradecimentos especiais são devidos à superintendência de Araraquara do DAEE, na figura do geólogo José Luiz Mendonça.

\section{Referências}

Atkins J.E. \& McBride E.F. 1992. Porosity and packing of Holocene river, dune, and beach sands. AAPG Bull., 76(3):339-355.

Crabtree Jr S., Ehrlich R., Prince C. 1984. Evaluation of strategies for segmentation of blue-dyed pores in thin sections of reservoir rocks. Computer Vision, Graphics, and Image Processing, 28:1-18.

Ehrlich R., Crabtree S.J., Horkowitz K.O., Horkowitz J.P. 1991. Petrography and reservoir physics I: Objective classification of reservoir porosity. AAPG Bull., 75(10):1547-1562.

Ehrlich R., Kennedy S.K., Crabtree S.J., Cannon R.L. 1984. Petrographic image analysis, I. Analysis of reservoir pore complexes. Jour. Sedim. Petrol., 54(4):1365-1378.

Gesicki A.L.D. 2007. Evolução Diagenética das Formações Pirambóia e Botucatu (Sistema Aquífero Guarani) no Estado de São Paulo. Tese de Doutoramento, IGc-USP, $175 \mathrm{p}$.

Glover P.W.J. 2000. Petrophysics. University of Aberdeen, England, 281p.

Gonzalez R.C. \& Woods R.E. 1992. Processamento de Ima- gens Digitais. São Paulo, Editora Edgard Blücher, 509p. Graton L.C. \& Fraser H.J. 1935: Experimental study of permeability and porosity of clastic sediments. Jour. Geology, 43:785-909.

Griffiths J.C. 1952. Grain size distribution and reservoir-rock chacacteristics. AAPG Bull., 36(2):205-229.

Kahn J.S. 1956. The analysis and distribution of the properties of packing in sand-size sediments. Jour. Geology, 64:385-395.

Petruk W. 1989. Image analysis of minerals. In: Petruk W. (ed.) Short Course on Image Analysis Applied to Mineral and Earth Sciences. Mineralogical Association of Canada, p. 6-18.

Schimdt V. \& McDonald D.A. 1979. Texture and recognition of secondary porosity in sandstones. SEPM Special Publication, 26:209-225.

Manuscrito ID 11592

Submetido em 26 de junho de 2008 Aceito em 21 de junho de 2009 